\title{
Relationship Between Arterial Oxygen Saturation and Hematocrit, and Effect of Slow Deep Breathing on Oxygen Saturation in Himalayan High Altitude Populations
}

\author{
Nepal O, ${ }^{1}$ Pokharel BR, ${ }^{1}$ Khanal K, ${ }^{2}$ Mallik SL, ${ }^{1}$ Kapoor BK, ${ }^{1}$ Koju R ${ }^{3}$
}

${ }^{1}$ Department of Physiology

${ }^{2}$ Department of Community Medicine

${ }^{3}$ Department of Internal Medicine

Dhulikhel Hospital, kathmandu University Hospital Kathmandu University Medical School, Dhulikhel Kavre, Nepal

\section{Corresponding Author}

Ojashwi Nepal

Department of Physiology

Kathmandu University School of Medical Sciences

Chaukot, Kavre, Nepal

Email: ojan2nep@gmail.com

Citation

Nepal O, Pokharel BR, Khanal K, Mallik SL, Kapoor BK, Koju R. Relationship Between Arterial Oxygen Saturation and Hematocrit, and Effect of Slow Deep Breathing on Oxygen Saturation in Himalayan High Altitude Populations. Kathmandu Univ Med J 2012;39(3):30-34.

\begin{abstract}
Backgroud

The oxygen saturation of haemoglobin is reduced in high altitude-living organisms. Increase in the hematocrit is responsible for rise in the hemoglobin concentration so that the oxygen carrying capacity in the hypobaric hypoxic subject is elevated.

\section{Objectives}

To compare two different high altitude populations, in order to study the relationship between arterial oxygen saturation and hematocrit.

\section{Methods}

IIn the cross-sectional study of two populations residing at altitude of $2800 \mathrm{~m}$ and $3760 \mathrm{~m}$ are compared for the difference in hematocrit. The oxygen carrying capacity of arterial haemoglobin $\left(\mathrm{SaO}_{2}\right)$ is determined by pulse oximetry. The sample is drawn from the natives of two small villages, Thini at Jomsom $(2800 \mathrm{~m})$ and Jharkot $(3760 \mathrm{~m}$ ) in Mustang district of Nepal. The natives at $2800 \mathrm{~m}$ are termed as lower high altitude population and local residents at $3760 \mathrm{~m}$ are said to be higher altitude population in this study. The sample blood was drawn by venipuncture and packed cell volume was determined by Wintrobe's method.
\end{abstract}

\section{Results}

The hematocrit obtained from $3760 \mathrm{~m}$ altitude population and the lower high altitude population at altitude of $2800 \mathrm{~m}$ differ significantly with the $\mathrm{p}$ value < 0.0001 and the $\mathrm{SaO} 2$ in both the population fails to show any difference with $p$ value $>0.05$. Deep breathing exercise in these populations however increased $\mathrm{SaO}_{2}$ significantly.

\section{Conclusion}

The higher altitude natives have greater arterial oxygen saturation than lower altitude population which is due to rise in red cell concentration. The slow deep breathing raises oxygen saturation irrespective of altitude.

\section{KEY WORDS}

High altitude, hematocrit, pulse, oximeter, $\mathrm{SaO}_{2}$, slow deep breathing 


\section{INTRODUCTION}

Some 140 million people are reported to inhabit at altitudes over 2500 m, mainly in North, Central, and South America, Asia, and eastern Africa. ${ }^{1}$ High-altitude environments provide scientists with a natural laboratory to study the physiological effects of hypobaric hypoxia on endemic highlanders. ${ }^{2}$ The native highlanders have a long history of exposure and opportunity of natural selection. ${ }^{3}$ Therefore, they show adaptive phenotypic features with respect to physiological parameters such as oxygen saturation, haemoglobin concentration, hypoxic ventilatory rate and blood pressure. ${ }^{4-8}$ Studies performed in Sherpas living permanently at high altitude suggest they are genetically better adapted to altitude than populations residing at the same altitude in Andes and highlands of Peru. ${ }^{9,} 10$ Though samples among highlanders of different part of the world are compared to Himalayan high altitude natives, the comparison among native population at two different altitudes of Himalayan population is performed in this study. The population included in this study is not Sherpas but the two different native ethnic groups, Gurung and Thakali at Mustang district of Western Nepal. In the present study two populations residing at altitude of $2800 \mathrm{~m}$ and $3760 \mathrm{~m}$ were compared for the difference in hematocrit, and the oxygen carrying capacity of arterial haemoglobin $\left(\mathrm{SaO}_{2}\right)$ were determined by pulse oximetry. We hypothesized there exists the relationship between $\mathrm{SaO}_{2}$ and $\mathrm{Hct}$ in high altitude population. In addition, the effect of deep breathing on $\mathrm{SaO}_{2}$ was compared in these populations.

The oxygen saturation of haemoglobin is reduced in high altitude-living organisms. The resulting hypoxic condition stresses the metabolic processes of an individual for want of oxygen. ${ }^{11}$ In order to maintain normal arterial oxygen content, the hypoxic stimulus increases red cell count in the circulation. Increase in the hematocrit is responsible for rise in the hemoglobin concentration so that the oxygen carrying capacity in the hypobaric hypoxic subject is elevated. A measure of hypoxemia is the percent of arterial hemoglobin that is saturated with oxygen $\left(\mathrm{SaO}_{2}\right)$. We wanted to see how the oxygen saturation is maintained in the higher altitude natives with respect to the lower high altitude natives and the difference in the arterial oxygen saturation after a slow deep breathing exercise on these local residents.

\section{METHODS}

The cross-sectional study of two Himalayan populations was conducted from $15^{\text {th }}$ Nov-15 $5^{\text {th }}$ Dec of 2010 . These local residents are inhabitants of this altitude for generations in the past.

The sample is drawn from the natives of two small villages, Thini $(2800 \mathrm{~m})$ and Jharkot $(3760 \mathrm{~m}$ ) in Mustang district of Nepal. In this study, lower high altitude refers to Jomsom which is the market place closest to Thini $(2800 \mathrm{~m})$ and higher altitude is repeatedly used for Jharkot at 3760 $\mathrm{m}$ altitude above sea level. The volunteers who were subjected to the study were 35 at Thini and 40 at Jharkot in number. These inhabitants engage in agricultural, pastoral and religious activities on the slopes of surrounding high mountains. Many subjects those living in higher altitude visited market place to lower altitude frequently during their routine work and emigrated during winter to districts at low altitudes. In order to increase the sample size we have included the subjects from 12 years -75 years old volunteers in the study. The male volunteers were 17 and female were 18 in number at 2800 m; similarly, 17 male volunteers and 23 female volunteers participated in the study at $3760 \mathrm{~m}$ of altitude. In the sample obtained at 2800 $m$ altitude 21 subjects were at or below 40 years of age and 14 volunteers were above 40 years of age. At $3760 \mathrm{~m}$ above sea level 21 subjects were below 40 years of age and 19 subjects were 40 years or older. Healthy volunteers were included in the study after regular clinical examination which was based on the elaborate history obtained and subjects on medications for hypertension, diabetes or chronic pulmonary diseases were excluded from the study. None of the volunteers had symptoms for anaemia.

Written consent was obtained from the subject before the sample blood was drawn by venipuncture in order to fulfill the ethical guideline of Dhulikhel Hospital, Kavre. Three $\mathrm{ml}$ of sample blood obtained from the subject by aseptic technique was stored in vacutainer containing EDTA. Hematocrit was determined by centrifuge in Wintrobe tubes the same day of sample collection. In order to determine oxygen content of arterial hemoglobin, FingerPluse-Oximeter was employed. While seated in a warm environment, the left index finger of each subject was cleaned with alcohol and dried. Measurement of $\mathrm{SaO}_{2}$ was determined by the method described by Charles and Ralph. ${ }^{12,13}$ While seated in a warm environment, the left index finger of each subject was cleaned with alcohol and dried and the oximeter was slipped over the finger. The $\mathrm{SaO}_{2}$ readouts were allowed to stabilize over a period of at least $2 \mathrm{~min}$ and then monitored for several more minutes until the $\mathrm{SaO}_{2}$ value remained unchanged for a minimum of $10 \mathrm{sec}$. This entire process commonly took between 5 and $10 \mathrm{~min}$. This value was recorded as the subject's $\mathrm{SaO}_{2}$. For the effect of deep breathing on arterial oxygen saturation to be observed, regulated deep breathing exercise at the rate of 6 cycles/ min, 5 seconds inspiration and 5 seconds expiration for 4 minutes was performed by the subjects and the $\mathrm{SaO}_{2}$ was read by pulse-oximeter immediately thereafter. ${ }^{14-16}$ The two populations were compared for the hematocrit and $\mathrm{SaO}_{2}$ by using Prism software. Data were compared by using two-tailed unpaired t-test for the determination of difference in packed cell volume in native populations at two different altitudes. Two-tailed paired t-test was employed to see the difference in $\mathrm{SaO}_{2}$ before and after deep breathing in these populations. 


\section{RESULTS}

When $\mathrm{SaO}_{2}$ in lower high altitude and higher altitude population was compared, two-tailed unpaired t-test of $p$ value $=0.140208$ was found. Since $p$ value $>0.05$ there exists no difference in oxygen saturation between these populations.

Similarly, two tailed unpaired t-test was employed for the determination of difference in hematocrit between population at higher $(3760 \mathrm{~m})$ altitude and lower high altitude $(2800 \mathrm{~m})$. As depicted in the figure 1, the mean of Hct at higher altitude population (Jharkot) is 50.23 with standard error of mean 0.9745. Mean and SEM at lower high altitude natives (Jomsom) is $44.57 \& 0.9315$ respectively with $\mathrm{p}$ value $<0.0001$ with the confidence interval of $95 \%$ signified the greater hematocrit at altitude of $3760 \mathrm{~m}$ in Jharkot.

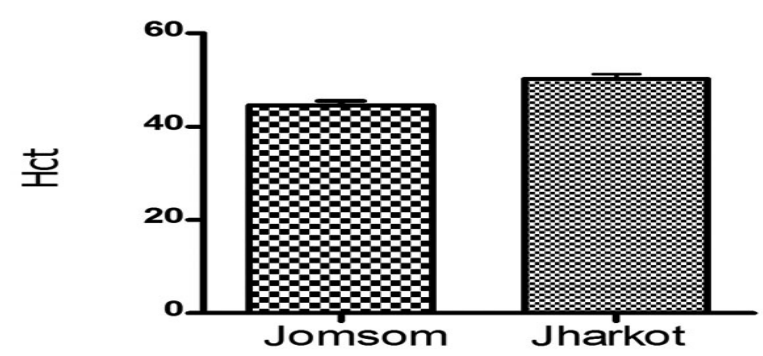

Figure 1. Difference in the mean of hematocrit (Hct) at altitude of $2600 \mathrm{~m}$ (Jomsom) and $3760 \mathrm{~m}$ (Jharkot) with the standard error of mean at the top of bar diagrams.

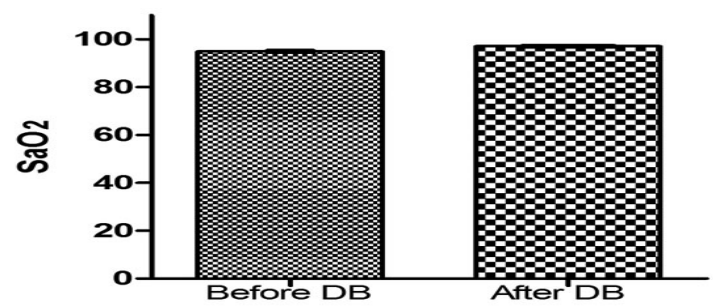

Figure 2. Difference in the mean of arterial oxygen saturation (SaO2) before and after deep breathing (DB) at altitude of $\mathbf{3 7 6 0}$ $\mathrm{m}$ (Jharkot) with the standard error of mean at the top of both bar diagrams.

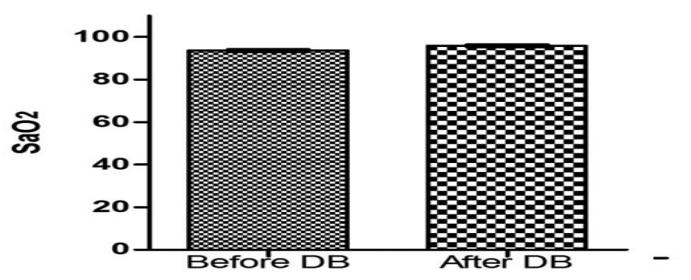

Figure 3. Difference in the mean of arterial oxygen saturation (SaO2) before and after deep breathing (DB) at altitude of $\mathbf{2 8 0 0}$ $\mathrm{m}$ (Jomsom) with the standard error of mean at the top of both bar diagrams.
Table 1. The age and sex distribution of subjects in Jharkot and Jomsom.

\begin{tabular}{|c|c|c|c|}
\hline \multicolumn{2}{|c|}{ JHARKOT } & \multicolumn{2}{|c|}{ JOMSOM } \\
\hline $\begin{array}{l}\text { Male } \\
\text { (Age) }\end{array}$ & $\begin{array}{l}\text { Female } \\
\text { (Age) }\end{array}$ & $\begin{array}{l}\text { Male } \\
\text { (Age) }\end{array}$ & $\begin{array}{l}\text { Female } \\
\text { (Age) }\end{array}$ \\
\hline 12 & 16 & 12 & 13 \\
\hline 13 & 18 & 12 & 18 \\
\hline 15 & 19 & 14 & 18 \\
\hline 21 & 19 & 14 & 19 \\
\hline 25 & 19 & 15 & 19 \\
\hline 25 & 28 & 16 & 19 \\
\hline 27 & 32 & 16 & 20 \\
\hline 27 & 35 & 22 & 20 \\
\hline 38 & 37 & 22 & 25 \\
\hline 39 & 39 & 37 & 30 \\
\hline 45 & 40 & 56 & 33 \\
\hline 46 & 45 & 63 & 51 \\
\hline 49 & 46 & 64 & 52 \\
\hline 50 & 47 & 67 & 55 \\
\hline 52 & 47 & 67 & 60 \\
\hline 55 & 48 & 68 & 75 \\
\hline \multirow[t]{7}{*}{61} & 50 & 71 & 65 \\
\hline & 50 & & 66 \\
\hline & 53 & & \\
\hline & 58 & & \\
\hline & 60 & & \\
\hline & 67 & & \\
\hline & 68 & & \\
\hline
\end{tabular}

At fig 2 and fig 3, the difference in the arterial oxygen saturation $\left(\mathrm{SaO}_{2}\right)$ before and after deep breathing exercise is depicted. It was determined by two tailed paired t-test in both the populations with $p<0.0001$ for the difference in $\mathrm{SaO}_{2}$ after deep breathing exercise at both altitudes with the confidence interval of $95 \%$ was found.

\section{DISCUSSION}

In this study $\mathrm{SaO}_{2}$ and Hct differences in two populations at different altitudes indicates that arterial oxygen saturation is high at higher altitude with increased packed cell volume than the population at relatively lower high altitude. Though earlier study in Sherpas living permanently at $4000 \mathrm{~m}$ above sea level, indicate they do not have increased hematological parameters (i.e., red cell number, hematocrit, hemoglobin content, and 2, 3-diphosphoglycerate/hemoglobin ratio) and have a higher affinity of blood for oxygen as compared with acclimatized Caucasians, this is not consistent for the two native populations included in this study as Gurung population at $3760 \mathrm{~m}$ have higher hematocrit than Thakali natives at $2800 \mathrm{~m}$ in an altitude difference of less than 1000 m. ${ }^{9}$

The populations included in this study at lower high altitude 
belonged to ethnic population of Thakali and at higher altitude were ethnic population of Gurung. The natives of high altitude practiced a habit of migrating to low lands during winter and descended frequently to market places at low lands at this district of Western Nepal. But, the findings of this study, to maintain $\mathrm{SaO}_{2}$ hematocrit should be increased at high altitude favors the fundamental physiology of erythropoietic response of raised packed cell volume in hypoxia induced stress at two different altitudes studied here. To calculate the $\mathrm{SaO}_{2}$ which can be considered normal for healthy people for every altitude below 4,200 $\mathrm{m}$, both before and after the acclimatization process is given in equations by Botella de Maglia J and Compte Torrero L. ${ }^{17}$

Since the very purpose of erythropoietin release in hypoxic stimulus is to raise the red cell count in order to keep normal arterial oxygen saturation, the finding in this study suggests that in order to maintain the $\mathrm{SaO}_{2}$ of higher altitude population there requires a higher Hct than lower high altitude natives. Gurung population at higher altitude with higher $\mathrm{SaO}_{2}$ and hematocrit than lower high altitude population signifies they are well adapted to hypobaric hypoxia. In an earlier study when high altitude westerners were compared for oxygen saturation, Sherpas had tendency toward higher arterial oxygen saturation than Westerners. ${ }^{18}$ Genetic adaptations in high altitude natives may permit adequate oxygenation and confer resistance to the syndrome of pulmonary hypertension and right-heart failure.

Pursed-lips breathing have been shown to improve gas exchange with increased $\mathrm{SaO}_{2}$ mainly by promoting slow and deep breathing pattern. ${ }^{19}$ Several mechanisms, e.g. recruitment of terminal airspaces and changes regarding the work of breathing, the ventilation-perfusion matching, the alveolar capillary pressure difference, or hemodynamic conditions, may be differently responsible for the improvement of oxygenation. ${ }^{20}$

$\mathrm{SaO}_{2}$ after deep breathing is more than before deep breathing in native population in this study irrespective of altitude. Deep breathing exercise improves resting pulmonary gas exchange. ${ }^{14}$

The feature of acclimatization to high altitude is an increase in red blood cell concentration that in turn results rise in haemoglobin concentration, and therefore oxygen carrying capacity. It means although the arterial $\mathrm{Po}_{2}$ and oxygen saturation are diminished, the oxygen content of the arterial blood may be normal or even above normal.
In the permanent residents at 4,540 $\mathrm{m}(15,000$ feet) in the Peruvian Andes, the arterial $\mathrm{Po}_{2}$ is only $45 \mathrm{mmHg}$ and the corresponding arterial oxygen saturation is only 81 percent. ${ }^{21}$ Ordinarily this would considerably decrease the arterial oxygen content but, because of the polycythemia, the hemoglobin concentration is increased from $15-19.8$ $\mathrm{g} / 100 \mathrm{ml}$, giving an arterial oxygen content of $22.4 \mathrm{ml} / 100$ $\mathrm{ml}$, which is above the normal sea level value.

In the present study, $\mathrm{Po}_{2}$ is not measured in the samples therefore to establish the corresponding $\mathrm{SaO}_{2}$ in the populations is not possible. The age distribution was from 12 -75 years old subjects, thus it cannot be told whether the increase in hematocrit to maintain $\mathrm{SaO}_{2}$ is essential in total population uniformly at higher altitude. Further study in young, young adults and elderly population for $\mathrm{Po}_{2}, \mathrm{Hb}$ concentration, $\mathrm{SaO}_{2}$ and hematocrit in these natives blood sample may unfold the age groups of local residents who are susceptible for hypobaric hypoxia thus they respond by increasing the hematocrit to maintain the oxygen saturation. Since slow deep breathing can improve oxygen saturation, the elderly population could be greatly benefitted from the simple and easy breathing technique. More study for the effectiveness of this tool in patients suffering from chronic heart failure and hypertension at low and high altitudes can be another exciting field of medical research.

\section{CONCLUSION}

The higher altitude natives have greater arterial oxygen saturation than lower altitude population which is due to rise in red cell concentration. This rise in hematocrit is an adaptation to hypobaric hypoxia at higher altitude of $3760 \mathrm{~m}$. The slow deep breathing raises oxygen saturation irrespective of age, gender and altitude. The breathing exercise may be more beneficial to older population residing in highlands.

\section{ACKNOWLEDGEMENTS}

The equipments for the study were provided by the help extended by $\mathrm{Dr}$ Biraj from Community Department of Dhulikhel Hospital. We thank Mr Karna Thakali, a health worker, at Thini Health Post for assistance in data collection and we are grateful to the residents of Thini and Jharkot for their cooperation with this study. We also wish to thank Dr Amin Shah for his invaluable time and advice, offered during data analysis.

\section{REFERENCES}

1. Moore LG, Niermeyer S, Zamudio S. Human adaptation to high altitude: regional and life-cycle perspectives. Am J Phys Anthropol 1998; Suppl 27:25-64.

2. Abigail WB, Mao X, Mei R, Brutsaert T, Megan J, Wilson et.al. Identifying positive selection candidate loci for high-altitude adaptation in Andean populations. Hum Genomics 2009; 4(2):79-90.

3. Ward MP, Milledge JS, West JB. High Altitude Medicine and Physiology. 3rd ed. London: Arnold Publishers; 2000.

4. Frisancho AR. Functional adaptation to high altitude hypoxia. Science 1975; 187:313-319.

5. Beall CM. Tibetan and Andean patterns of adaptation to high-altitude hypoxia. Hum Biol 2000; 72:201-228. 
6. Zhuang J, Droma T, Janes C. Hypoxic ventilator responsiveness in Tibetan compared with Han residents of 3,658 m. J. Appl. Physiol 1993; 74:303-311.

7. Katayama K, Sato Y, Morotome Y, Shima N, Ishida K, Mori S et.al. Cardiovascular response to hypoxia after indurance training at altitude and sea level and after detraining. J. Appl. Physiol 2000; 88(4):1221-1227.

8. Mirrakhimov MM, Winslow RM. In: Handbook of Physiology, section 4: Environmental Physiology; Fregly MJ, Blatteis CM, eds. New York: Oxford University Press; 1996.

9. Morpurgo G, Arese P, Bosia A, Pescarmona GP, Luzzana M, Modiano $\mathrm{G}$ et.al. Sherpas living permanently at high altitude: A new pattern of adaptation. Proc. Nat. Acad. Sci. U.S.A 1976; 73:747-751.

10. Beall CM, Brittenham GM, Macuaga F, Bargan M. Variation in hemoglobin in concentration among samples of high-altitude natives in the Andes and the Himalayas. Am. J. Hum. Biol 1990; 2:639-651.

11. Hochachka PW, Buck LT, Doll CJ, Land SC. Unifying theory of hypoxia tolerance: molecular/metabolic defense and rescue mechanisms for surviving oxygen lack. Proc. Natl. Acad. Sci. U.S.A 1996; 93(18):94939498.

12. Charles AW, Ralph MG. A comparative analysis of arterial oxygen saturation among Tibetans and Han born and raised at high-altitude. High Altitude Medicine \& Biology 2007; 8:1, 13-26.

13. Sinex JE. Pulse oximetry: principles and limitations. Am J Emerg Med 1999; 17(1):59-67.
14. Bernardi L, Spadacini G, Bellwon J, Hajric R, Roskamm H, Frey AW. Effect of breathing rate on oxygen saturation and exercise performance in chronic heart failure. The Lancet 1998; 351(9112):1308-1311.

15. Spicuzza L, Gbutti A, Porta C, Montano N, Bernardi L. Yoga and chemoreflex response to hypoxia and hypercapnia. The Lancet 2000; 356 (9240):1495-1496. Hackett PH, Reeves JT, Reeves CD, Grover RF, Remmi D. Control of breathing in Sherpas at low and high altitude. J. Appl. Physiol 1980; 49:374-9.

16. Bernardi L, Porta C, Spicuzza L, Bellwon J, Spadacini G, Frey AW et.al Slow breathing increases arterial baroreflex sensitivity in patients with chronic heart failure. Circulation 2002; 105:143-145.

17. Botella de Maglia J, Compte Torrero L. Arterial oxygen saturation at high altitude. A study on unacclimatized mountaineers \& mountain dwellers. Med Clin (Barc) 2005; 124(5):172-6.

18. Hackett PH, Reeves JT, Reeves CD, Grover RF, Remmi D. Control of breathing in Sherpas at low and high altitude. J. Appl. Physiol 1980; 49:374-9.

19. Mueller R, Petty T, Filley G. Ventilation and arterial blood gas changes induced by pursed-lips breathing. J Appl Physiol 1970; 28:784-789.

20. Burtscher M. Pursed-lips breathing for improved oxygenation at altitude. Sleep Breath 2009; 13(2):119-120.

21. West JB (ed.). Best \& Taylor's Physiological Basis of Medical Practice. 12th ed. Baltimore: Williams \& Wilkins: 1991. 